\title{
Use of the Er,Cr:YSGG Laser in the Treatment of Peripheral Ossifying Fibroma
}

\author{
Vidyaa Hari lyer, Sonali Sarkar, S Kailasam
}

\begin{abstract}
Ossifying fibroma mostly occurs in the craniofacial bones and is generally categorized into two types, namely, central and peripheral ossifying fibroma. The peripheral type occurs solely on the soft tissue overlying the alveolar process and is 'nonneoplastic'. It is a common gingival growth that usually arises from the interdental papilla. The etiology and pathogenesis of peripheral ossifying fibroma (POF) is unclear. It is thought to arise from the cells in the periodontal ligament. Trauma or local irritation, such as dental plaque, calculus, ill-fitting dental appliances and poor-quality dental restorations are all known to precipitate in the development of POF. Clinically, differential diagnosis includes peripheral giant cell granuloma, pyogenic granuloma, fibroma and peripheral fibroma. Treatment of POF consists of elimination of etiological factors, scaling and root planing of involved teeth and total aggressive surgical excision. Another option available in place of the conventional surgical excision is the excision using lasers. A new addition to this generation of lasers is Er,Cr:YSGG laser. The aim of this paper is to analyze the effectiveness of Er,Cr:YSGG laser in the treatment of POF. The outcome in this case was painless experience to the patient, minimal intraoperative bleeding in the surgical field and excellent healing of the operated area in 1 week period, concluding as one of the best treatment option available for excision of POF.
\end{abstract}

Keywords: Er,Cr:YSGG laser, Peripheral ossifying fibroma, Healing, Minimal bleeding.

How to cite this article: lyer VH, Sarkar S, Kailasam S. Use of the Er,Cr:YSGG Laser in the Treatment of Peripheral Ossifying Fibroma. Int J Laser Dent 2012;2(2):51-55.

Source of support: Nil

Conflict of interest: None declared

\section{INTRODUCTION}

Localized gingival enlargements are fairly common and typically represent reactive proliferative lesions, rather than true neoplasm. ${ }^{1-3}$ Reactive or inflammatory lesions represent more than $90 \%$ of histopathologically analyzed gingival biopsies and most commonly include diagnoses of pyogenic granuloma, fibrous hyperplasia, peripheral ossifying fibroma (POF) and peripheral giant cell granuloma. Ossifying fibroma occurs mostly in craniofacial bones and is generally categorized into two types, namely, central and peripheral. The central type arises from the endosteum or periodontal ligament adjacent to the root apex and expands from the medullary cavity of the bone. The peripheral type occurs solely on the soft tissue overlying the alveolar process and is a 'non neoplastic', reactive fibrous proliferation of gingiva. ${ }^{4,5}$

The POF is a common gingival growth usually arising from the interdental papilla. There is a gender difference, with $66 \%$ of the lesion occurring in females. The prevalence of POF is highest around 10 to 19 years of age. The peak incidence of POF is between the second and third decades. It appears only on the gingiva, more often on the maxilla rather than the mandible and is frequently found in the area around the incisors and canines. The adjacent teeth are usually not affected. ${ }^{6}$ POF is typically a solitary, slowly growing nodular mass that is either sessile or pedunculated with the size usually being less than $2 \mathrm{~cm}$; but patients with lesions of 6 and $9 \mathrm{~cm}$ in diameter have also been reported. ${ }^{7,8}$

The etiology and pathogenesis of POF is unclear. It is thought to arise from cells in the periodontal ligament. Trauma or local irritation, such as dental plaque, calculus, ill-fitting dental appliances and poor-quality dental restorations are all known to precipitate the development of POF. ${ }^{7}$

Clinically, differential diagnosis includes peripheral giant cell granuloma, pyogenic granuloma, fibroma and peripheral fibroma. ${ }^{10}$

Histopathological picture of POF can exhibit either an intact or an ulcerated stratified squamous epithelium. The deeper fibroblastic component is highly cellular with central areas of calcification. The mineralized tissue may consist of bone, cementum-like material, dystrophic calcification or a combination of each. Treatment of POF consists of elimination of etiological factors, scaling and root planing of involved teeth and total aggressive surgical excision along with involved periodontal ligament and periosteum to minimize the possibility of recurrence. ${ }^{9}$

Another option available in place of conventional surgical excision is the excision using lasers. Various soft tissue lasers, such as diode laser have been used. An Er,Cr: YSGG laser was used for the case presented in this article. It is a laser-powered hydrokinetic system that produces a wavelength absorbed maximally in water molecules and targets the hydroxyl groups of enamel and dentin. The wavelength of the Er,Cr:YSGG laser is 2,780 nm, which places this laser in the mid-infrared region of the electromagnetic spectrum. The energy produced by the Er,Cr:YSGG laser demonstrates good absorption by water and to a lesser degree by hydroxyapatite. ${ }^{11-13}$ Because all dental tissues contain water, the Er,Cr:YSGG laser is useful for many dental procedures. Enamel contains approximately $3 \%$ water and dentin contains approximately $12 \%$ water. $^{14}$ Bone and cementum have approximately $15 \%$ water slightly 
higher when compared with dentin and the soft tissue has the highest water content, i.e. greater than $70 \%$. The water contained in enamel, dentin, cementum, bone and soft tissue absorbs the energy produced by the Er,Cr:YSGG laser and the result is ablation of the target tissue. Less laser energy is required to ablate soft tissue than enamel. The medium, which enables photon amplification includes heterogenous crystals of yttrium, scandium, gallium, garnet. The crystal matrix also contains dopants (erbium and chromium) to enhance the performance of the laser emission. ${ }^{15}$

There are numerous benefits to using this type of laser in the surgical treatments. Rapid healing can be observed within a few days of the treatment, and as blood vessels are sealed, there is both reduced need for post-surgical dressings and improved hemostasis and coagulation. It also depolarizes nerves, thus reducing postoperative pain and destroys many bacterial and viral colonies that may potentially cause infection. Reduced postoperative discomfort, edema, scarring and shrinkage have all been associated with its use. ${ }^{16,17}$

The need for analgesics and anti-inflammatory medication has been reduced considerably. In some treatments, there is no need for local anesthesia, while in others, a smaller amount as compared to the conventional techniques is used. Recent reports in the dental literature describes the successful use of this laser for surgical procedures. ${ }^{17}$

The aim of this article is to analyze the effectiveness of Er,Cr:YSGG laser in the treatment of POF and to observe the pain, bleeding and healing.

\section{CASE REPORT}

A 25-year-old, male patient had visited the Department of Oral Medicine and Radiology at Ragas Dental College and Hospital, Chennai, Tamil Nadu, India, with the chief complaint of a growth in the lower right front tooth region for the past 1 month. He gave a history of the growth appearing suddenly and it grew slowly to the present size in the lower right front tooth region arising from the gingiva. No pain was experienced by the patient. He had noticed the growth while brushing. No relevant medical history was given by the patient. On intraoral examination, there was solitary pedunculated growth arising from the interdental papillae on the buccal surface (Fig. 1) in relation to 41 and 42 measuring about $4 \times 5 \mathrm{~mm}$ in size, arising inferiorly from the interdental papilla between 41 and 42 and extending superiorly up to the middle $1 / 3$ rd of 41 and 42 , mesially up to the distal 1/3rd of 41 and distally covering almost the lower and middle 1/3rd of 42. Lingually, in between 41 and 42, a single growth was present measuring $3 \times 4 \mathrm{~mm}$ in size (Fig. 2). Both the lesions appeared to be of

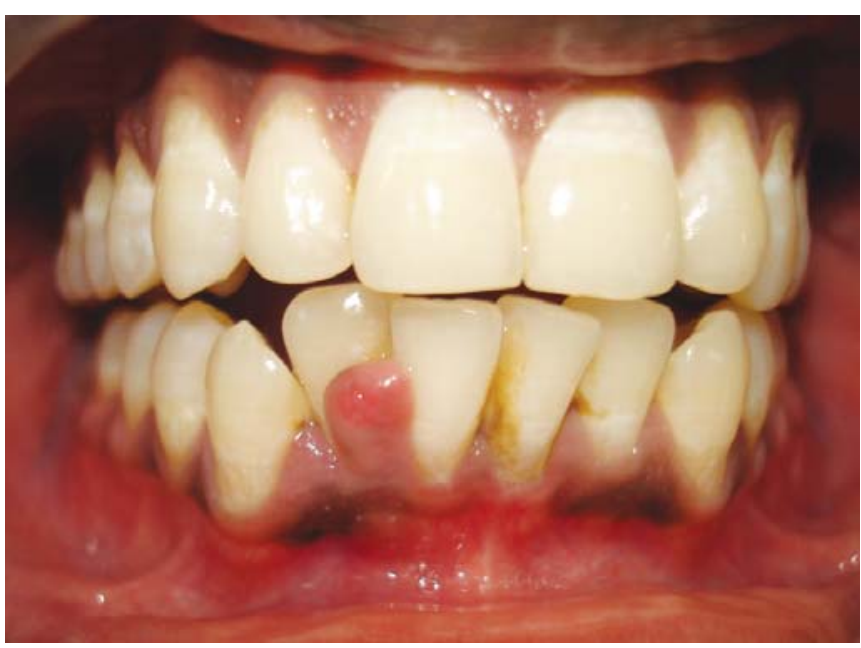

Fig. 1: Intraoral photograph of buccal lesion before scaling and root planing

same color as that of the gingiva, without any secondary changes. On palpation all the findings of inspection related to the size, site, shape and the extent of the lesion were confirmed. The lesion was firm in consistency, non-tender on palpation. Supragingival calculus was present. The growth was then provisionally diagnosed as pyogenic granuloma involving the interdental papilla region between 41 and 42.

The patient was then referred to the Department of Periodontics for root scaling and planing. After the periodontal treatment, the patient was kept under observation for 1 week in order to confirm whether the lesion regressed after the removal of the local factors, such as calculus. After 1 week, the buccal lesion remained the same even after the removal of the stimuli (Fig. 3). But the lingual lesion totally regressed within a week after scaling and root planing (Fig. 4). The patient was then referred to Smile Dental Clinic, T Nagar, Chennai, Tamil Nadu, India for excision of the lesion by laser. The growth was excised using Er,Cr:YSGG laser (Waterlase MD, Biolase, USA) with the settings of the laser in $\mathrm{H}$ mode, $1.50 \mathrm{~W}$, air-30\% and water10\%, MT , 25 Hz. (Fig. 5). The excision was done using a sapphire tip (Fig. 6). No topical anesthesia or local anesthesia was administered. No antibiotics or analgesics were provided after the procedure. Throughout the procedure the patient did not experience any pain and there was only minimal bleeding (Fig. 7). The excised specimen (Fig. 8) was then sent for histopathological analysis.

The microscopic examination revealed stratified squamous epithelium with irregular acanthosis and submucosal chronic inflammation and perivascular inflammation (Fig. 9). Foci calcifications were seen (Fig. 10) and the lesion was histopathologically diagnosed as POF involving the interdental papilla between 41 and 42 . 


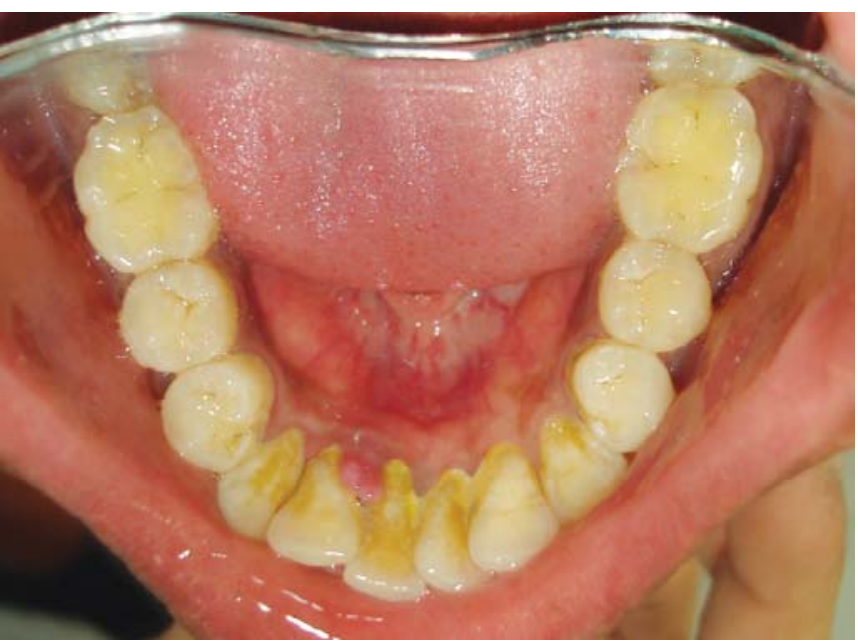

Fig. 2: Lingual lesion before scaling and root planing (mirror image)

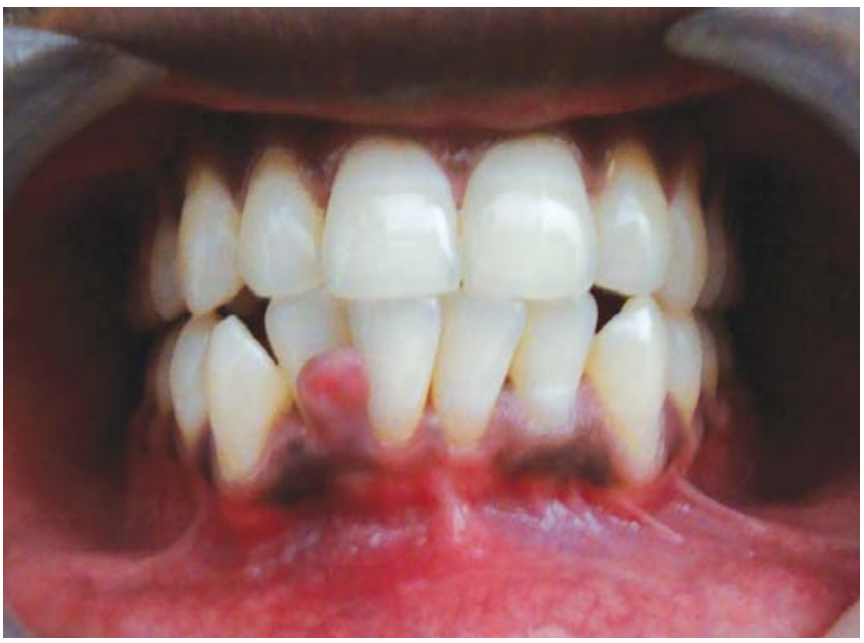

Fig. 3: Preoperative buccal lesion 1 week after scaling and root planing

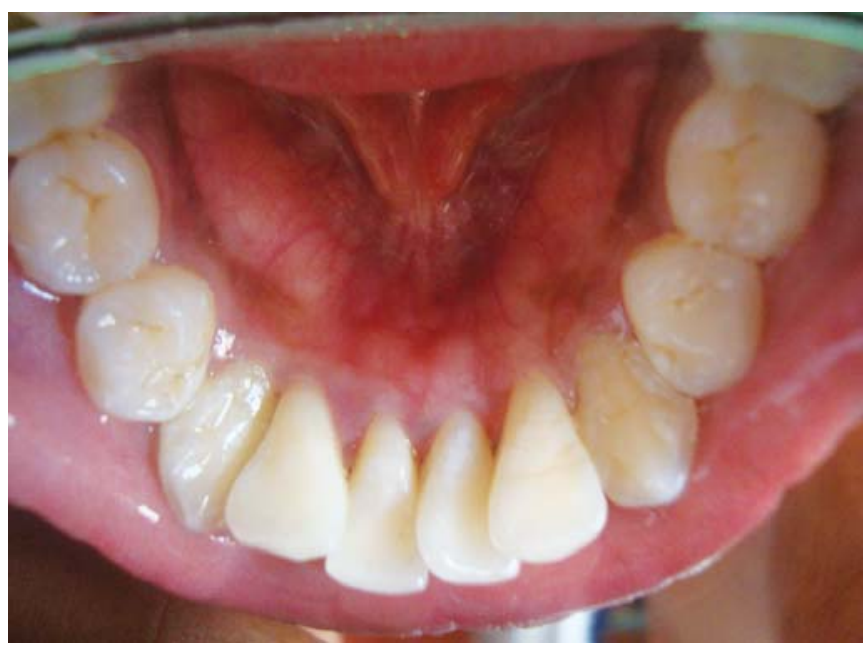

Fig. 4: Regression of the lingual lesion 1 week after scaling and root planing (mirror image)

The patient was then recalled 1 day after the excision of the lesion by laser for a postoperative review (Fig. 11) when he was observed for initiation of healing. The patient

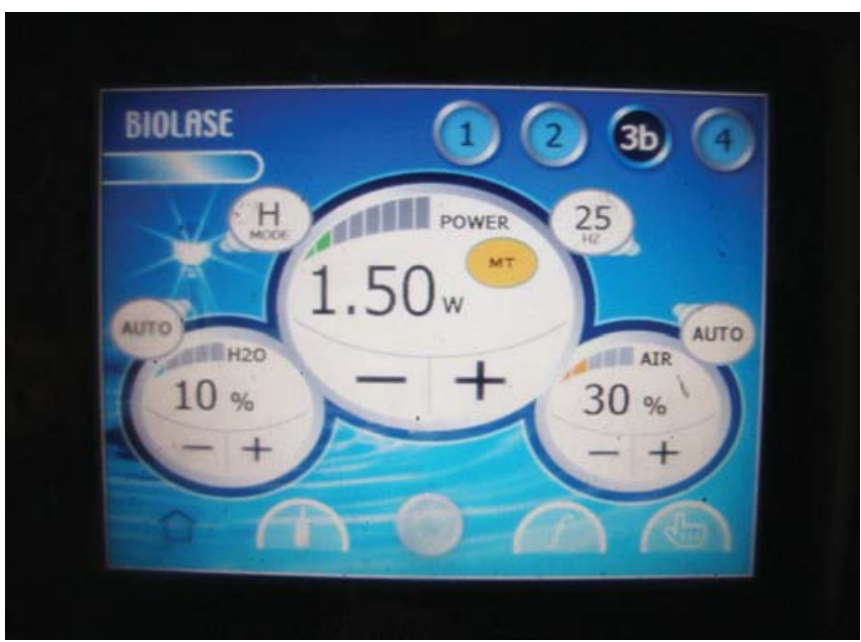

Fig. 5: Er,Cr:YSGG laser settings

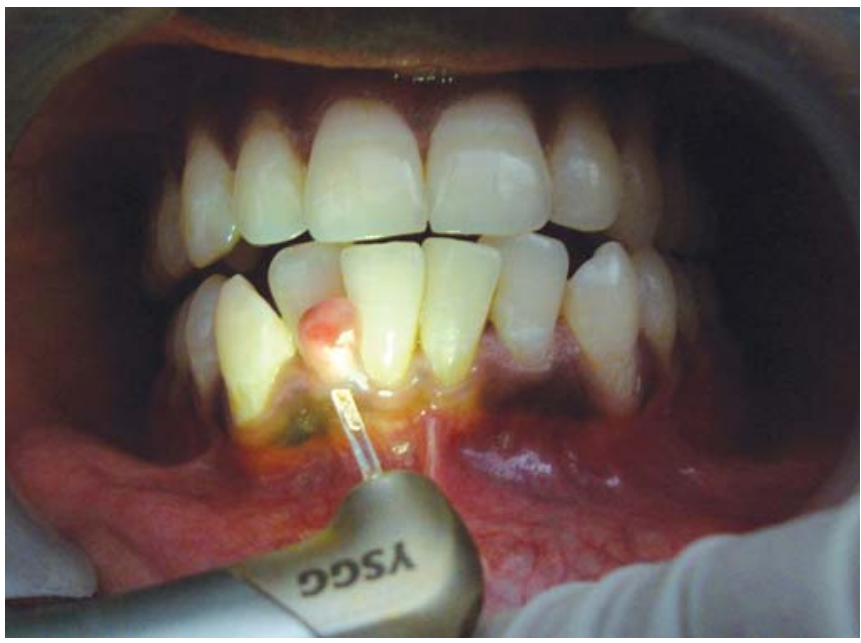

Fig. 6: Er,Cr:YSGG laser with gold handpiece and sapphire tip used for excision of the lesion

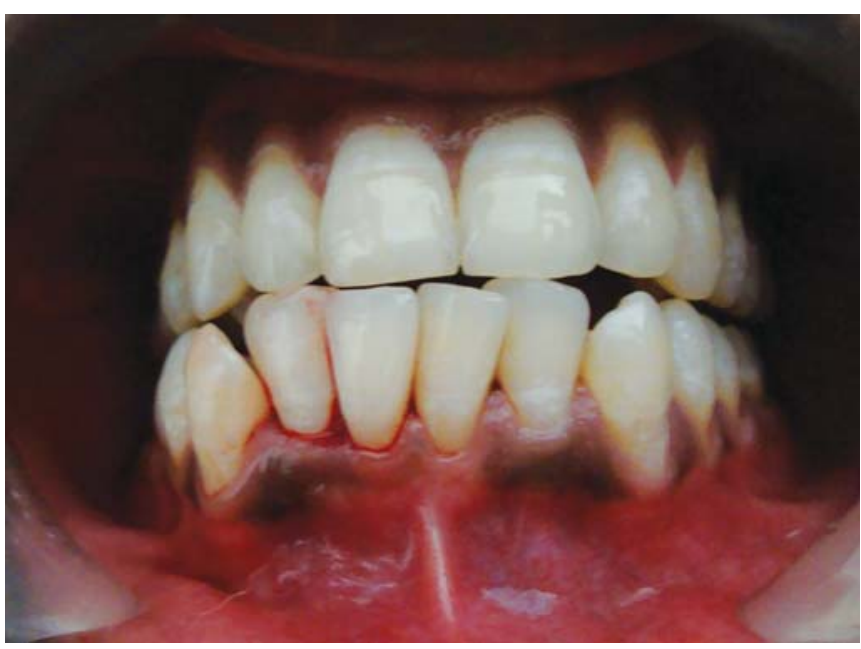

Fig. 7: Postoperative site immediately after excision of the buccal lesion

did not experience any pain or discomfort after 1 day and healing had initiated without any complications. The patient was again recalled 1 week after the surgery for review 


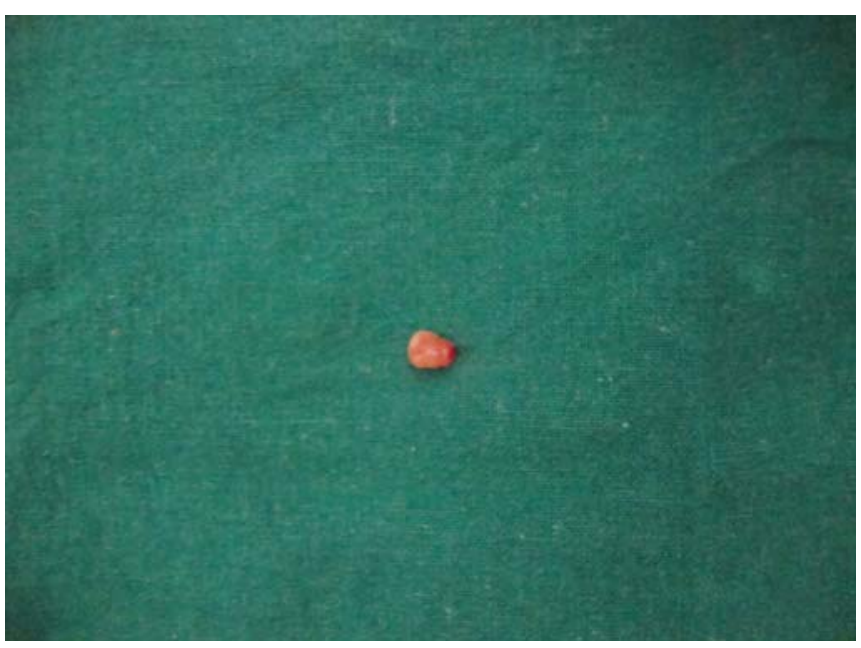

Fig. 8: Tissue of the buccal lesion after excision

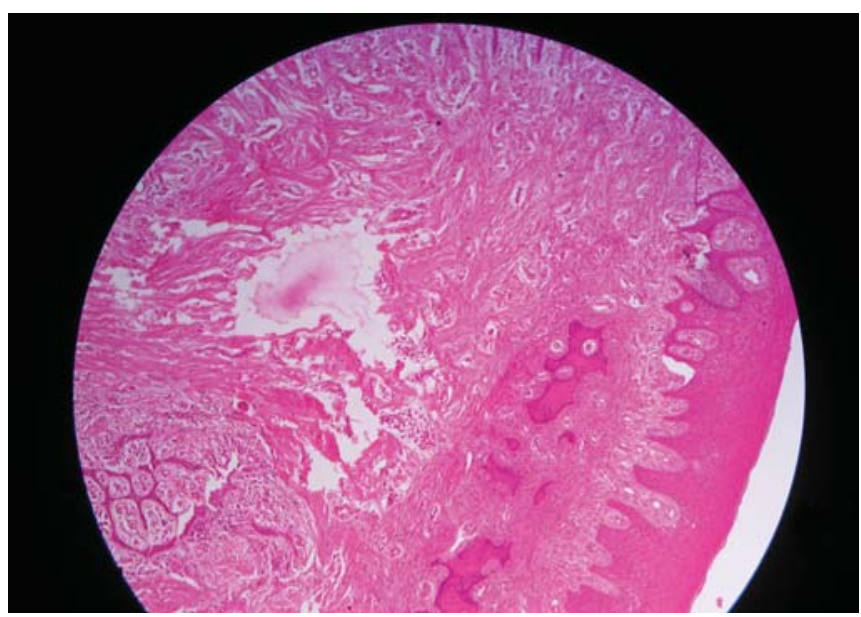

Fig. 9: Histopathological picture confirming POF (20x resolution)

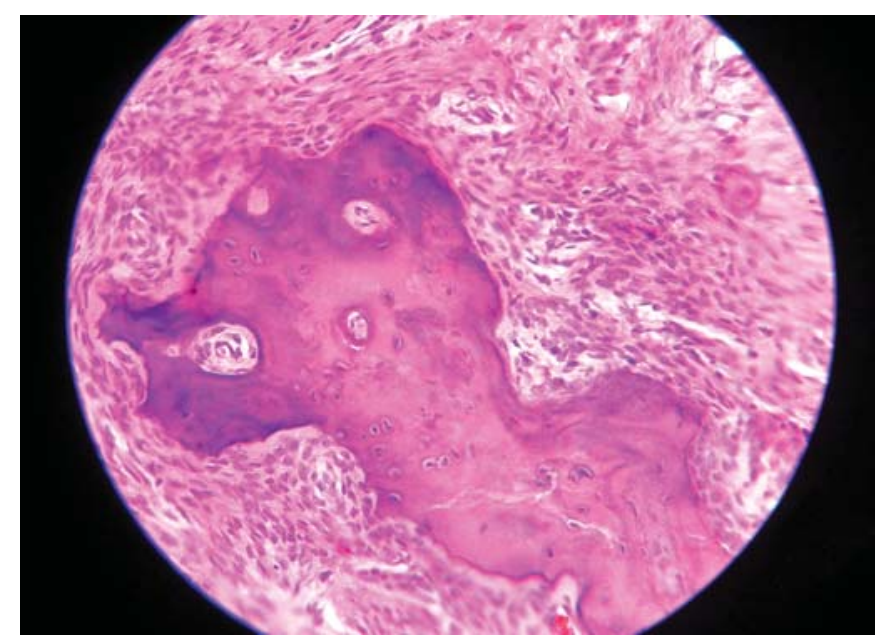

Fig. 10: Histopathological picture of POF with foci of calcification ( $40 \times$ resolution)

(Fig. 12). Complete healing of the excision site was observed with normal interdental papilla between 41 and 42 .

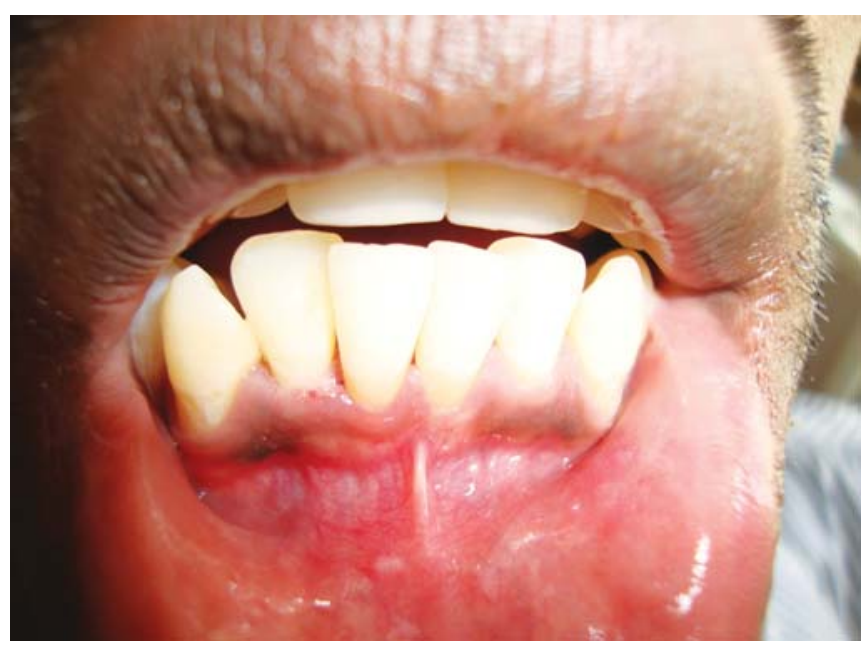

Fig. 11: Field of excision (between 41 and 42) 1 day after the procedure

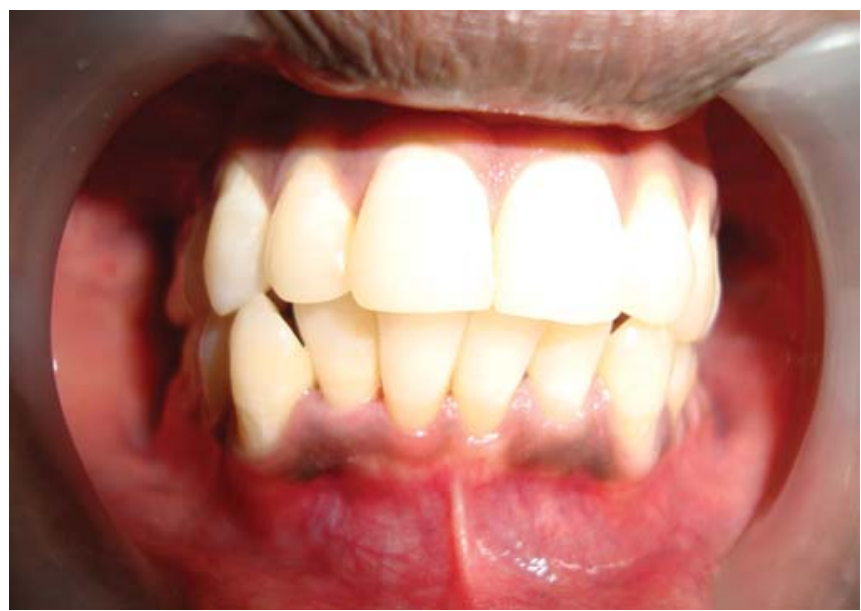

Fig. 12: Field of excision (between 41 and 42 ) 1 week after the procedure

\section{CONCLUSION}

Peripheral ossifying fibroma has always been described as a solitary, slow-growing nodular mass treated by scalpel excision. The case described here has been treated with Er,Cr:YSGG laser with sapphire tip. The Er,Cr:YSGG laser has proved excellent for dealing with such lesion. No suture was necessary. The patient experienced no pain or any discomfort. The intraoperative bleeding was minimal and the postoperative healing was excellent. It may be necessary to treat a series of such lesions with laser excision so that the recurrence pattern of these lesions, if any, can be established, thus confirming the efficacy of Er,Cr:YSGG laser. A long-term follow-up is also required to understand if any late complication arises with the use of Er,Cr:YSGG laser.

This reported lesion was on a male patient occurring in between the incisor teeth in the mandible, thus making the case unique. 


\section{ACKNOWLEDGMENT}

We would like to personally thank Dr R Padmapriya for her consistent help throughout this case report.

\section{REFERENCES}

1. Bhaskar SN, Levin MP. Histopathology of the human gingival (study based on 129 biopsies). J Priodontol 1973;44(1):3-17.

2. Stablein MJ, Silverglade LB. Comparative analysis of biopsy specimens from gingival and alveolar mucus. J Periodontol 1985;56(11):671-76.

3. Van del Waal I. Non-plaque related periodontal lesions. An overview of some common and uncommon lesions. J Clin Periodontol 1991;18(6):436-40.

4. Moon WJ, Chai SY, Chung EC, Kwon KH, Chae SW. Peipheral ossifying fibroma in the oral cavity: CT and MR findings. Dentomaxillofac Rad 2007;36:180-82.

5. Neville BW, Down DD, Allen C, et al. Textbook of oral and maxillofacial pathology (2nd ed). West Philadephia: Saunders 2004:451-52.

6. Kahn MA. Basic Oral and Maxillofacial Pathology. http:// en.wikipedia.org/wiki/Peripheral_ossifying_fibroma.

7. Kendrick F, Waggoner WF. Managing a peripheral ossifying fibroma. J Dent Child 1996;63:135-38.

8. Eversole LR, Rovin S. Reactive lesions of the gingiva. J Oral Pathol 1972; 1:30-38.

9. Prasad S, Reddy SB, Patil SR, Kalburgi NB, Puranik RS. Peripheral ossifying fibroma and pyogenic granuloma are they interrelated?. NYSDJ March 2008:50-52.

10. Cuisia ZE, Brannon RB. Peripheral ossifying fibroma: A clinical evaluation of 134 pediatric cases. Pediatr Dent 2001;23:245-48.

11. Eversole LR, Rizoiu IM. Preliminary investigations on the utility of an erbium, chromium: YSGG laser. J Calif Dent Assoc 1995;23(12):41-47.
12. Eversole LR, Rizoiu IM, Kimmel AI. Pulpal response to cavity preparation by an erbium, chromium:YSGG laser-powered hydrokinetic system. J Am Dent Assoc 1997;128(8):1099-106.

13. Hadley J, Young DA, Eversole LR, et al. A laser-powered hydrokinetic system for caries removal and cavity preparation. J Am Dent Assoc 2000;131(6):777-78.

14. Arends, J, Ruben JL, Inaba D. Major topics in quantitative microradiography of enamel and dentin: $\mathrm{R}$ parameter, mineral distribution visualization, and hyper-remineralization. Adv Dent Res 1997;11(4):403-14.

15. Rizoiu I, Kohanghadosh F, Kimmel Al, Eversole LR. Pulpal thermal responses to erbium , chromium:YSGG pulsed laser hydrokinetic system. Oral Surg Oral Med Oral Pathol Oral Radiol Endod 1998;86:220-23.

16. Boj J. The future of laser pediatric dentistry. J Oral Laser Applic 2005; 5:173-77.

17. Schoop U, Kluger W, Mortiz A, Nedjelik N, Georgopoulos A, Sperr W. Bactericidal effect of different laser systems in the deep layers of dentin. Laser Surg Med 2004;111-16.

\section{ABOUT THE AUTHORS}

\section{Vidyaa Hari lyer (Corresponding Author)}

Private Practitioner, Smile Dental Clinic, T Nagar, Chennai, Tamil Nadu India, e-mail: vidyaahari@gmail.com

\section{Sonali Sarkar}

Postgraduate Student, Department of Oral Medicine and Radiology Ragas Dental College and Hospital, Chennai, Tamil Nadu, India

\section{S Kailasam}

Professor and Head, Department of Oral Medicine and Radiology Ragas Dental College and Hospital, Chennai, Tamil Nadu, India 